\title{
INFLUENCE OF AIR INJECTION ON SUCTION POWER AND PRESSURE GRADIENT IN DREDGER SYSTEM
}

\author{
Mohammad MESHKATI SHAHMIRZADI ${ }^{1}$, Tetsuya SUMI ${ }^{2}$, Sameh KANTOUSH $^{3}$ \\ and Toshiyuki TEMMYO 4 \\ ${ }^{1}$ Member of JSCE, Ph.D. candidate, Disaster Prevention Research Institute, Kyoto University (Gokasho, Uji, Kyoto \\ 611-0011, Japan) \\ ${ }^{2}$ Member of JSCE, Professor, Disaster Prevention Research Institute, Kyoto University (Gokasho, Uji, Kyoto \\ 611-0011, Japan) \\ ${ }^{3}$ Member of JSCE, Associate Professor, Faculty of Engineering and Material Science, German University of Cairo \\ (New Cairo City, Al-Tagamoa Al-Khames, Cairo, Egypt) \\ ${ }^{4}$ Member of JSCE, Ph. D., HAZAMA Corp. (2-2-5 Toranomon Minatoku, Tokyo, Japan)
}

\begin{abstract}
Air injection could be a possible solution to prevent blockage along the transport pipeline which commonly occurs during the operation of dredger system. The present paper seeks to investigate the influence of air injection on the performance of dredger system by injecting variant air concentrations. To achieve this purpose, the experiments were conducted under various operating condition such as: initial pump pressure $(0.196,0.294,0.490$ and $0.706 M P a)$, sediment grain sizes $(2,5,10 \mathrm{~mm}$, Mixed and Large), transport sediment concentrations $(0.8 \%$ to $8.5 \%)$ and air concentrations $(0,25,40,60$ and $100 \mathrm{nl} / \mathrm{min})$. The experiments showed that the risk of pipeline blockage is higher in case of fine sediment compared with coarser sizes. Furthermore, the air injection into the system is more effective for lower initial pump pressure $(0.196$ and $0.294 \mathrm{MPa})$. Also, the lowest pressure gradient along the transport pipeline was observed for the specific air concentration ranges from 40 to $60 \mathrm{nl} / \mathrm{min}$ and specific sediment concentration ranges from $3.5 \%$ to $6 \%$.
\end{abstract}

Key Words: Reservoir sedimentation, ejector pump dredger system, multiphase flow, pressure gradient,

\section{INTRODUCTION}

Utilizing the dredger system is an effective technique to solve the problematic of sedimentation in reservoir storage. The most sever challenge that frequently observed during the operation of dredger system is the blockage of transport pipeline; defined as an occasion in which dredger system is unable to maintain the vacuum and transport anymore sediment to the disposal site. In such a condition, introducing air into the transport pipeline could be an operative option to reduce the risk of blockage in dredger system. By injection of air a complex three-phase of air, water, and sediment flow will be created along the transport pipeline. The experimental studies in the area of three-phase flow were mostly conducted in petroleum and chemical engineering and rarely in water engineering.

In summary, the reported investigations can be classified into three main categories: (a) Flow and sand dunes pattern study ${ }^{1), 2)}$., (b) Sand particles motion study ${ }^{3), 4)}$ (c) Pressure drop study 5), 6), 7), 8).

The characteristics of sand particles (grain size, specific weight, density, cohesiveness) prevailing on present dredger system is slightly different from what were dominant on above mentioned studies. The sand particles used in these studies are almost fine, light and cohesive, with high suspension rate into the liquid phase, which named slurries. While the present dredging system mainly aimed to vacuum the coarser sediment (gravels) rather than finer one. 
Take into account that, the dredger system should also be able to transport the large woods and garbage, which already vacuumed into the system. In this case, the proper design of dredger system is very important to prevent the high possibility blockage risk inside of the system.

In other hand, the experimental studies conducted in oil drilling operation and cuttings transport were under specific hydraulic condition such as: a rotation part at the beginning of transport pipeline, extra liquid polymeric solutions, pressure of sea water column, and temperature variation.

Although the results of these studies are relevant to the concept of three-phase flow in transport pipeline of dredger system, their applicability for the purpose of an efficient design are uncertain. The main objective of this study is to experimentally investigate the properties of the turbulent three-phase flow (air-water-sediment) in transport pipeline of dredger system. For this purpose, extensive experiments were conducted to clarify the effect of air injection concentration on suction power, efficiency and pressure gradient in the dredger system.

\section{MATERIALS AND METHODS}

(1) Experimental apparatus and instrumentation

The experimental model used in this study is shown in Fig. 1. This model consists of three parts:

(1) Initial Force Section: includes a high pressure pump $(P)$ and its water storage tank $\left(T_{l}\right)$. When the pump is operating and valve $(V)$ is opened, clear water can be withdrawn from $T_{1}$ and discharged out of the nozzle. The pump pressure $\left(P_{P}\right)$ was measured by a pressure gauge $(G)$, and then the relative initial water flow rate $\left(Q_{w l}\right)$ was calculated.

(2) Suction Section: includes ejector house $(E H)$, suction pipeline $(S P)$ with $3 m$ length and inner diameter of $25 \mathrm{~mm}$, and second storage tank $\left(T_{2}\right)$. Due to the low (negative) pressure domain just after the nozzle section, a pressure gradient was created between entrance of suction pipeline and inside of the system, which it caused mixed of water and sediment vacuumed (sucked up) from $T_{2}$ into $E H$.

(3) Transport Section: includes transparent transport pipeline $(T P)$ with $10 \mathrm{~m}$ length and inner diameter of $36 \mathrm{~mm}$, and external storage tank $\left(T_{3}\right)$.

Transport pipeline conveyed the sediment to the disposal site, and fluids were released into the external tanks $\left(T_{3}\right)$. Air, also, was injected into the transport pipeline by a compressor $(A C)$ and a dynamic pressure gauge $(D G)$ with three piezometers and a high speed camera $(C C D)$ were incorporated to measure the differential pressure between locations $P_{t 1}$ to $P_{t 3}$ and monitor the flow

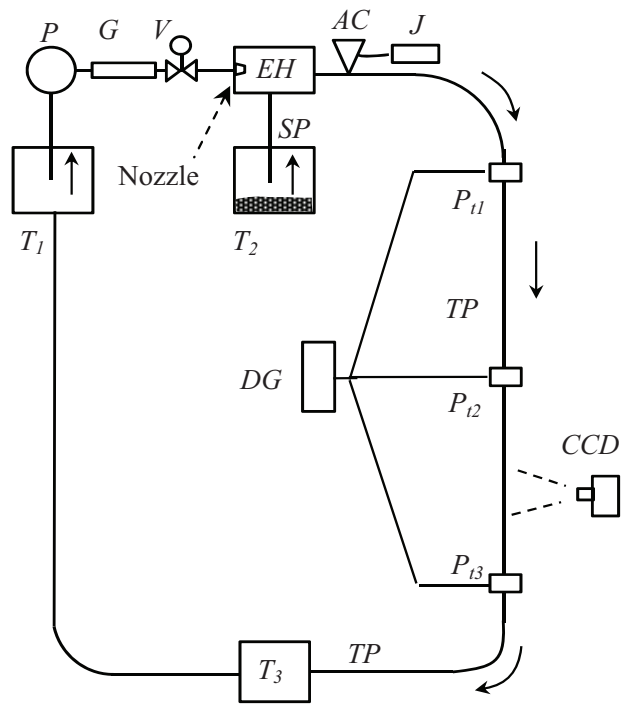

Fig. 1 The schematic view of model setup.

pattern in $T P$, respectively. The locations of each piezometer points were selected on straight pipeline section how the distance between each point were $3.5 \mathrm{~m}$, as illustrated in Fig. 1. In order to inspect the trustworthiness of the data acquired by dynamic pressure gage $(D G)$, some preliminary experiments were conducted aim to measure the pressure gradient along the pipeline in laminar steady state; which indicated that the data acquisition is reliable.

\section{(2) Definition of main parameters}

The suction power $\left(Q_{s u c}\right)$, transport efficiency of the system $(E)$ and pressure gradient $(\Delta p)$ were considered as three main criteria to evaluate the performance of dredger system. The $Q_{\text {suc }}$ is defined as Eq. (1):

$$
Q_{s u c}=Q_{s}+Q_{w 2}
$$

where $Q_{s}$ and $Q_{w 2}$ are sediment and water removal rate from $T_{2}$, respectively. Suction power $\left(Q_{\text {suc }}\right)$ can be acquired by Eq. (2):

$$
Q_{s u c}=\frac{V_{s w}}{\Delta t}
$$

where $V_{s w}$ is the volume of water and sediment vacuumed into the system and $\Delta t$ is the total time needed to evacuate all the deposit sediment from $T_{2} . V_{s w}$ was obtained by deferential of water level in $T_{2}$ before and after each test. Moreover, the transport efficiency of system $(E)$ can be simply deliberated from Eq. (3):

$$
E=\frac{Q_{s}}{Q_{w 1}}
$$

where $Q_{w l}$ is the initial water flow rate that is entered to the $E H$ through the nozzle and $Q_{s}$ is the sediment removal rate from $T_{2}$, which can be simply 
obtained by Eq. (4):

$$
Q_{s}=\frac{V_{s}}{\Delta t}
$$

where $V_{s}$ is the initial volume of deposit sediment at the bottom of $T_{2}$ and $\Delta t$ is the total time needed for each experiment to vacuum specific amount of sediment $\left(V_{s}=2\right.$ liter $)$. Lastly, the ratio of average differential pressure between first piezometer $\left(P_{t 1}\right)$ and third piezometer $\left(P_{t 3}\right)$ over the length distance $(\Delta x)$ between these two points were considered as pressure gradient $(\Delta p)$, as Eq. (5):

$$
\Delta p=\frac{p_{t 1}-p_{t 3}}{\Delta x}
$$

The length distance $(\Delta x)$ between the first and third point was 7 meter. Moreover, the sediment concentration ( $\mathrm{Cop}$ ) was defined as below:

$$
\text { Cop }=\frac{Q_{s}}{Q_{w 1}+Q_{w 2}}
$$

\section{(3) Experiment procedure}

To carry out the experiments, the high pressure pump $(P)$ was set to supply four different pump pressures: $0.196,0.294,0.490$ and $0.706 \mathrm{MPa}$, resulting in four different initial flow rates of 17.2, 25, 32 and $36 \mathrm{l} / \mathrm{min}$. At first, $T_{2}$ was filled with clear water and a certain amount of sediment (2 liter). When dredger system started to operate, sediment and water were vacuumed into the $E H$ and pushed forward through the transport pipeline by the force of initial water flow rate. The three phases were injected into the transport pipeline at different combination of volumetric flow rates including: air concentration $(0,25,60$ and $100 \mathrm{nl} / \mathrm{min})$, sediment grain size $(2,5,10 \mathrm{~mm}$, Mixed and Large) and sediment concentrations $(0.89 \%$ to $8.5 \%)$. Before any data recording actions, each test was allowed to run 2 to 5 minutes for being stabilize along the $T P$ and reach to the equilibrium condition. Then the time needed to vacuum the all sediment (2 liter) that already have stored on the bottom of $T_{2}$ was recorded. To specify the volume of sediment and water removed from $T_{2}$, the water elevation inside of $T_{2}$ at the beginning and at the end of each experiment was measured.

\section{RESULTS AND DISCUSSION}

\section{(1) Effect of air injection on suction power}

Fig. 2 and 3 show the variation of suction power $\left(Q_{\text {suc }}\right)$ versus the pump pressure $\left(P_{p}\right)$ for different grain size of sediment. The cases shown in Fig. 2 are related to the sediment transport in pipeline just by the force of pump pressure without any air injection into the dredger system (experiment with water and sediment). However, for the cases

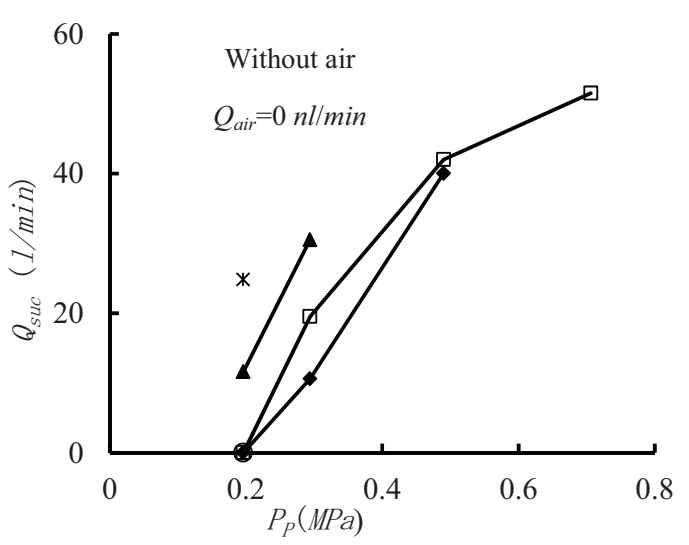

Fig. 2 Relationships between suction power $\left(Q_{s u c}\right)$ and pump pressure $\left(P_{p}\right)$ for no air injected to the system, $Q_{\text {air }}=0 \mathrm{nl} / \mathrm{min}$ and different grain size, data points are: *, Large; $\boldsymbol{\wedge}, 10 \mathrm{~mm} ; \circ$, Mixed; $\square, 5 \mathrm{~mm} ; \bullet, 2 \mathrm{~mm}$.

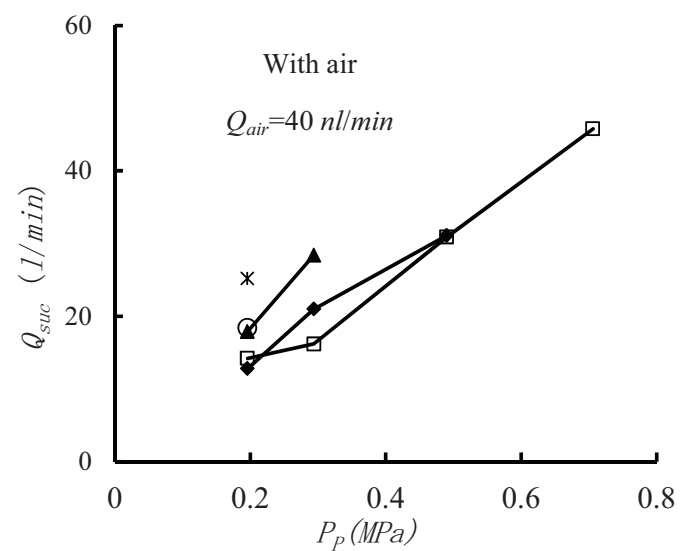

Fig. 3 Relationships between suction power $\left(Q_{s u c}\right)$ and pump pressure $\left(P_{p}\right)$ for $40 \mathrm{nl} / \mathrm{min}$ air injected to the system, $Q_{\text {air }}=40$ nl/min and different grain size, data points are: *, Large; $\mathbf{\Delta}, 10$ $\mathrm{mm} ; \circ$, Mixed; $\square, 5 \mathrm{~mm} ; \bullet, 2 \mathrm{~mm}$.

illustrated in Fig. 3, in addition to the different pump pressure, $40 \mathrm{nl} / \mathrm{min}$ air was introduced into the $T P$. Comparing these two figures revealed that when the pump pressure was relatively low $\left(P_{p}=0.196\right.$ $M p a)$ and no air injected into the system, sediment transport capacity was almost zero, specifically for fine sediment $\left(d_{s}=2,5 \mathrm{~mm}\right.$ and Mixed). In other words, pipeline blockage was occurred $\left(Q_{s u c}=0\right.$ $l /$ min) and no sediment had the chance to be transported in the pipeline.

On the contrary, by injecting $40 \mathrm{nl} / \mathrm{min}$ air into the $T P$, the pipeline blockage solved and suction power $\left(Q_{\text {suc }}\right)$ drastically improved. Indeed, injection of air into the system increased the superficial velocity of flow in $T P$, and then the sediment had less chance for deposition. Comparing Fig. $\mathbf{2}$ and $\mathbf{3}$ indicate that, at low initial pressure pump $\left(P_{p}=0.196 \mathrm{MPa}\right)$ and fine sediment $\left(d_{s}=2,5 \mathrm{~mm}\right.$ and Mixed), the risk of 
blockage in system is higher comparing with coarse sediment $\left(d_{s}=10 \mathrm{~mm}\right.$ and Large). Inspection of data revealed that fine and coarse sediment has characteristically different behavior versus air injection into the transport pipeline. When no air introduced in $T P$, more commonly fine sediment tends to form sand dunes along the transport pipeline, whereas coarse sediments were transported more individually. Therefore, fine sediment may create higher roughness against the flow and consequently greater pressure gradient.

In other side, when air supplied into the system the intermittent wavy flow (slug flow) was created along the TP and fine sediment easily suspended in the body of each coming wave and flushed out. Indeed, with changing the rate of injected air or water various flow patterns could be identified along the horizontal pipeline such as: stratified flow, plug flow, slug flow, dispersed flow and etc. Slug flow is an intermittent wavy flow that mostly forms in two-phase and three-phase flow. The characteristics of slug flow (intermittent wavy) were already well described by Tippetts \& Priestman ${ }^{1)}$. Moreover, introducing air into the system in case of relatively high-pressure pump has not any positive effect on the suction power $\left(Q_{\text {suc }}\right)$ of system. Comparing Fig. $\mathbf{2}$ and $\mathbf{3}$ indicate that for high initial pressure pump (0.490 and $0.706 \mathrm{Mpa})$, by injecting air into the transport pipeline the suction power $\left(Q_{\text {suc }}\right)$ slightly reduced. At the low pump pressure (i.e.17.2 Mpa) the sediment transport pattern along the transport pipeline is either stationary bed or movable bed; in which the effect of surface friction between the flow and pipe wall is considerably high. Air injection can reduce the surface friction between the flow and pipe wall by suspending the sediment into the slug flow body.

In case of fine sediment due to the less load and high potential to be fully suspended, the air injection was operative. In other hand, at high-pressure pump the sediment transport pattern is either moving bed flow or asymmetric suspension flow. In this case air injection increases the turbulent of flow and creates numbers of eddies, resulting in loss of energy and reduction of suction power $\left(Q_{\text {suc }}\right)$.

Therefore, a critical velocity can be obtained for three-phase flow inside of horizontal pipeline for which the injection of air and its subsequently increasing the velocity until it reaches to critical velocity can increase the suction power; while the velocity over the critical velocity can decrease the suction power.

\section{(2)Effect of air injection on efficiency of system}

Fig. 4 and $\mathbf{5}$ depict the relationships between efficiency of system $(E)$ and air concentration $\left(Q_{\text {air }}\right)$

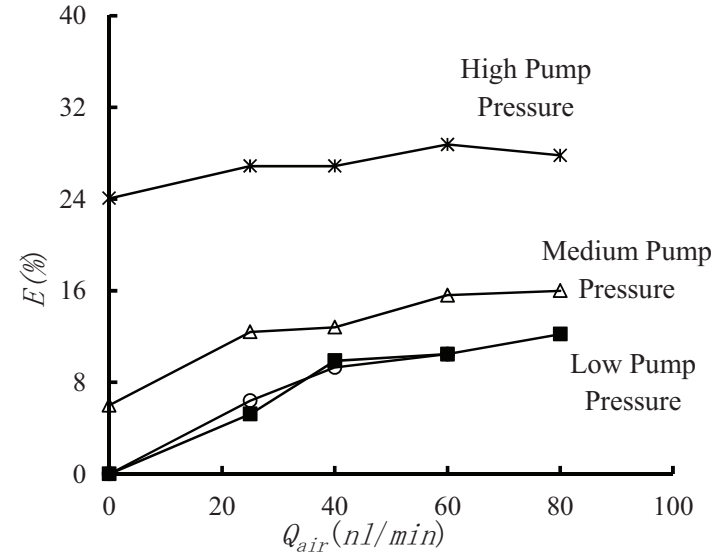

Fig. 4 Relationships between efficiency $(E)$ and air concentration $\left(Q_{\text {air }}\right)$, data points are: $-d_{s}=2 \mathrm{~mm}, P_{P}=0.196$ $M P a ; \circ, d_{s}=$ Mixed, $P_{P}=0.196 \mathrm{MPa}$; $\triangle, d_{s}=2 \mathrm{~mm}, P_{P}=0.294 \mathrm{MPa} ; *, d_{s}=2 \mathrm{~mm}, P_{P}=0.490 \mathrm{MPa}$.

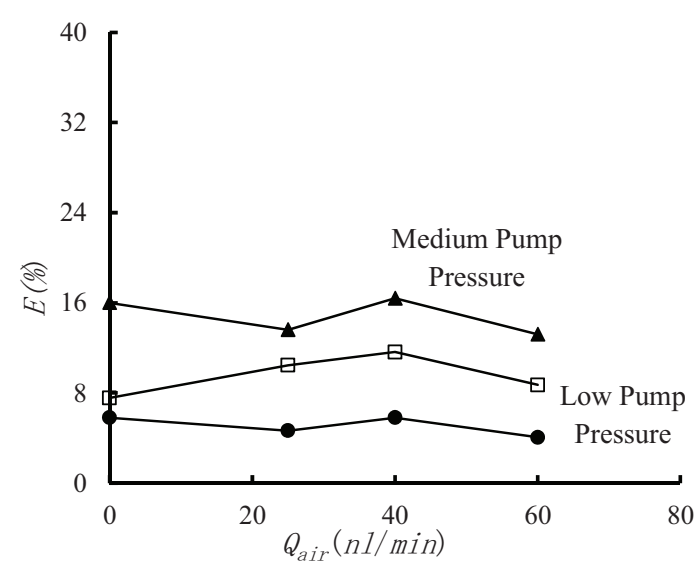

Fig. 5 Relationships between efficiency $(E)$ and air concentration $\left(Q_{\text {air }}\right)$, data points are: $\bullet, d_{s}=$ Large, $P_{P}=0.196 \mathrm{MPa} ; \square, d_{s}=10 \mathrm{~mm}, P_{P}=0.196 \mathrm{MPa} ; \boldsymbol{\Delta}, d_{s}=10 \mathrm{~mm}$, $P_{P}=0.294 \mathrm{MPa}$.

for group of fine $\left(d_{s}=2 \mathrm{~mm}\right.$ and Mixed) and coarse sediment $\left(d_{s}=10 \mathrm{~mm}\right.$ and Large), respectively. As shown in Fig. 4, for fine sediment, increasing the concentration of air $\left(Q_{\text {air }}\right)$ continually improved the efficiency of dredger system $(E)$. However, the same overall trend was not observed with respect to the coarse sediment (Fig. 5). Indeed, the higher concentration of air $\left(Q_{\text {air }}\right)$ positively intensified the suspension of fine sediment into the slug flow body. Therefore, fine sediment could be transported in longer distance by slug flow. While for coarse sediment, each particle of sediment makes its own friction against the driven force of flow and hardly suspend in slug flow body.

(3)Effect of air injection on pressure gradient

Fig. 6 to 8 illustrates the variation of pressure gradient $(\Delta p)$ versus the sediment concentration 
$(C o p)$. As can be seen in these figures, the pressure gradient $(\Delta p)$ was relatively high when no air $\left(Q_{a i r}=0 \mathrm{nl} / \mathrm{min}\right)$ was introduced into the system. While by injecting an intermediate concentration of air $\left(Q_{\text {air }}=60 \mathrm{nl} / \mathrm{min}\right)$, the pressure gradient $(\Delta p)$ considerably reduced and that is why the air injection into the system could solve the pipeline blockage for fine sediment, as shown in Fig. 2 and 3. Adversely, introducing a high concentration of air $\left(Q_{\text {air }}=100 \mathrm{nl} / \mathrm{min}\right)$ into the $T P$, showed a negative impact that caused the increase of pressure gradient $(\Delta p)$ in system. Furthermore, as exhibited in these figures, the pressure gradient $(\Delta p)$ became proportionally greater with increasing the transport sediment concentration ( $\mathrm{Cop}$ ). Particularly, when the experiments were carried out without any air injection $\left(Q_{\text {air }}=0 \mathrm{nl} / \mathrm{min}\right)$ sediment particles settled at the bottom of $T P$ and created a stationary bed inside of the pipeline. Resulting in a hydrodynamic radius of $T P$ became smaller and accordingly the friction of pipeline and the pressure gradient $(\Delta p)$ were increased. Nevertheless, as can be seen in Fig. 6 to $\mathbf{8}$, for a specific range of sediment concentration $(C o p=3.5 \%$ to $6 \%)$ and particular air concentration $\left(Q_{\text {air }}=60 \mathrm{nl} / \mathrm{min}\right)$, as sediment concentration ( Cop $)$ increased the pressure gradient $(\Delta p)$ reduced. This result is generally in good agreement with the result obtained by Okayama ${ }^{5}$, where they explained the reduction of pressure loss for soft mud slurry with air in case of high solid concentration. And it is in contradiction with the result reported by Bjerkholt ${ }^{7}$ who noted that no significant reduction in pressure gradient will be occurred as a result of air addition into the transport pipeline. Indeed, increase of sediment concentration means the growth of the particles quantity inside of the transport pipeline. As a result of exist turbulent in the pipeline, the tiny air bubbles consistently can enter to the slug flow body and exit again. When the quantity of sediment particles increased, more tiny air bubbles can be absorbed between the sediment particles. These tiny air bubbles positively can reduce the settling velocity of those sediments, which already suspended in the slug flow body. Hence, sediment can be transported in longer distance by a wave. It noteworthy to mention that the air in $T P$, generally has an inherent tendency to scape and gather at the upper part of pipeline and make a bigger bubble. A bigger bubble means the greater gap between each slug flow. Then by injecting too much air the distance between each slug flow will be increased and thus sediment particles have enough time to redeposit on the bottom of $T P$. While injecting an optimal concentration of air could adjust a proportion gap between each slug flow how the next coming slug flow will arrive and flushed sediment

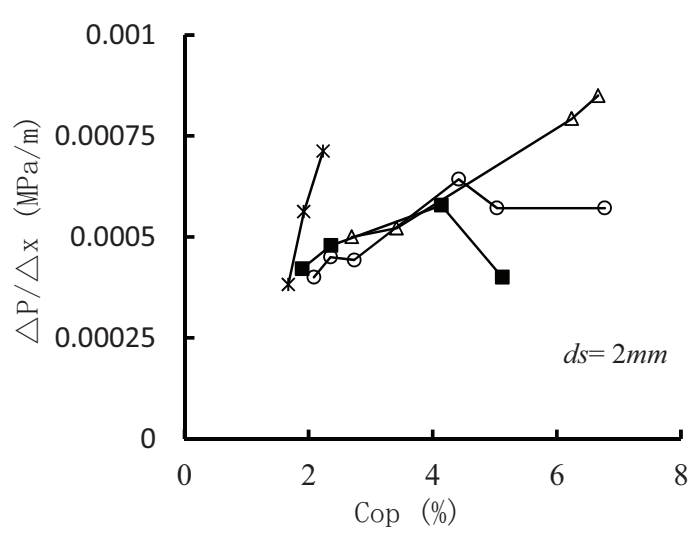

Fig. 6 Relationships between pressure gradient $(\Delta p)$ and concentration of sediment ( $C o p$ ) in transport pipeline for given $P_{P}=0.196 \mathrm{MPa}$ and $d s=2 \mathrm{~mm}$ and different concentrations of air, data points are: $*, 0 \mathrm{nl} / \mathrm{min} ; \circ, 25 \mathrm{nl} / \mathrm{min} ; \mathbf{\square}, 60 \mathrm{nl} / \mathrm{min}$; $\Delta, 100 \mathrm{nl} / \mathrm{min}$

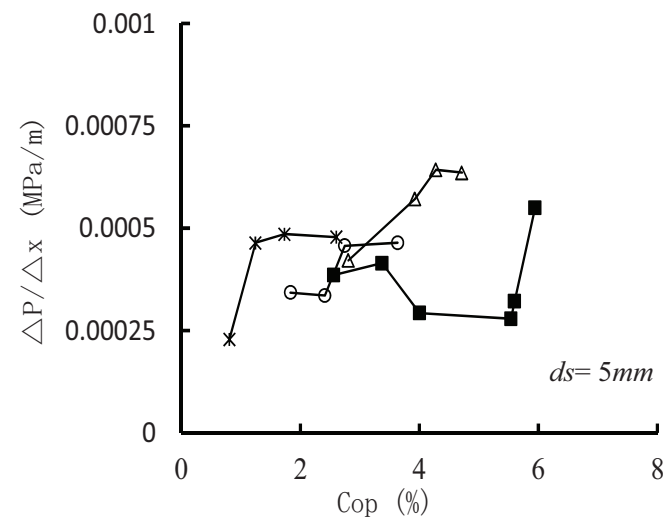

Fig. 7 Relationships between pressure gradient $(\Delta p)$ and concentration of sediment $(C o p)$ in transport pipeline for given $P_{P}=0.196 \mathrm{MPa}$ and $d s=5 \mathrm{~mm}$ and different concentrations of air, data points are: *, $0 \mathrm{nl} / \mathrm{min} ; \circ, 25 \mathrm{nl} / \mathrm{min} ; \mathbf{\square}, 60 \mathrm{nl} / \mathrm{min}$; $\Delta, 100 \mathrm{nl} / \mathrm{min}$.

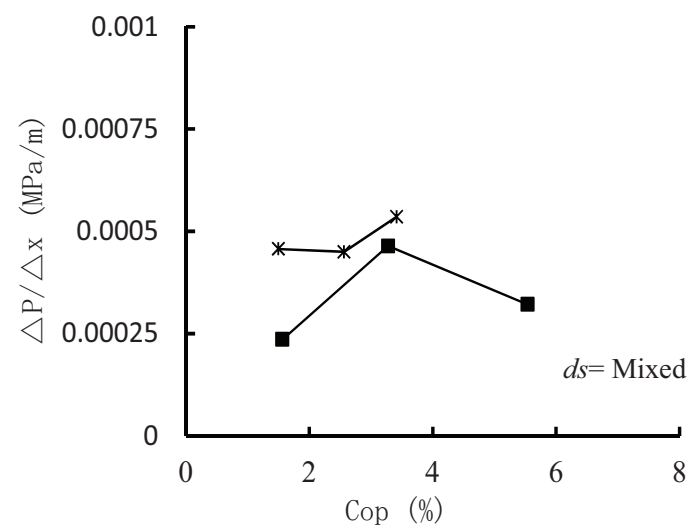

Fig. 8 Relationships between pressure gradient $(\Delta p)$ and concentration of sediment $(\mathrm{Cop})$ in transport pipeline for given $P_{P}=0.196 \mathrm{MPa}$ and $d s=$ Mixed and different concentrations of air, data points are: $*, 0 \mathrm{nl} / \mathrm{min} ; \mathbf{\square}, 60 \mathrm{nl} / \mathrm{min}$.

toward the downstream area before re-deposition of sediment particles. 


\section{(4) Velocity distribution by using LSPIV}

Large-scale particle image velocimetry (LSPIV) was used to evaluate the variation of flow velocities in $T P$. This technique is now widespread and extensive researches exist on this topic ${ }^{9)}$. Fig. 9 presents the velocity distribution of two-phase flow (water-sediment) in TP when no air was added into the system.

As shown on this treated image, almost all velocity vectors confined to the upper half of $T P$ and were ordered into the direction of stream-wise flow and create a laminar velocity profile inside of $T P$. In this case, no velocity vectors visualized for the sediment deposited at the bottom of TP. However, when 40 $n l / m i n$ air injected into the system (Fig. 10), the velocity distribution was significantly affected by presence of air. In fact, by injecting air into the $T P$ an intermittent wavy flow pattern (slug flow) was created and the velocity vectors periodically oriented towards the bottom of TP. Resulting in the sediment deposited on the bottom of TP was effectively slid forward then held up and lastly suspended into the slug flow body. The maximum velocity magnitude in this case was observed at the bottom of $T P$.

Likewise, based on the LSPIV analysis mainly for low initial pump pressure, the relationships between average velocity of flow and air concentration was investigated. The results proof that an optimum concentration of air should be injected into the system to reach a maximum velocity in the $T P$ (in range 40 to $60 \mathrm{nl} / \mathrm{min}$ ), depend on the sediment concentration and initial pump pressure.

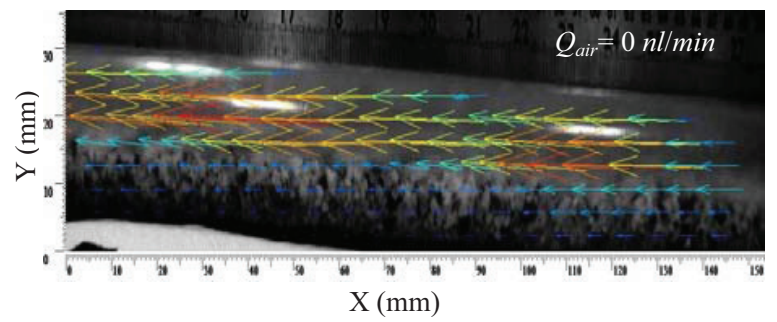

Fig. 9 The average velocity distribution of the multiphase flow in transport pipeline, $d_{s}=2 \mathrm{~mm}, P_{P}=0.196 \mathrm{MPa}, Q_{\text {air }}=0 \mathrm{nl} / \mathrm{min}$.

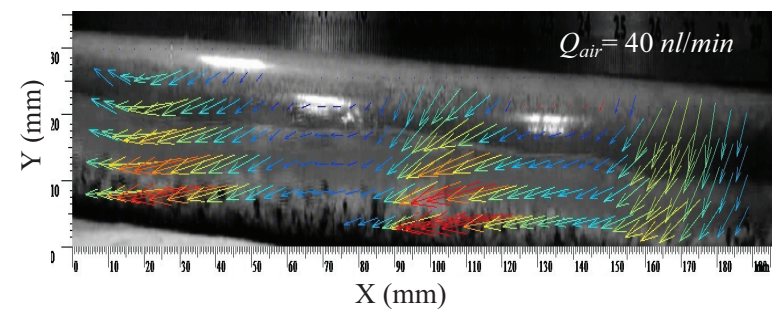

Fig. 10 The average velocity distribution of the multiphase flow in transport pipeline, $d_{s}=2 \mathrm{~mm}, P_{P}=0.196 \mathrm{MPa}, Q_{\text {air }}=40 \mathrm{nl} / \mathrm{min}$.

\section{CONCLUSION}

The following conclusions were drawn in this paper: (a) The risk of pipeline blockage by fine sediment was substantially more than coarse sediment and it more often happened in case of low initial pump pressure. (b) Air injection into the transport pipeline could prevent the pipeline blockage. (c) Injection of air has no significant impact on performance of dredger system in case of high initial pressure pump. (d) To achieve the maximum performance of dredger system, it is recommended to utilize an intermediate concentration of air and relatively high concentration of sediment. (e) A tendency for reduction of pressure gradient was observed for an optimal fraction of air, water and sediment in the pipeline.

\section{REFERENCES}

1) Tippetts, J. R. and Priestman, G. H.: Mobility of Solids in Multiphase undulating Pipe Flow, Proceeding of the Seventh international Conference of Multiphase Production, Cannes, Franc, June 18-20, 1997.

2) Goharzadeh, A., Rodgers, P., and Touati, C.: Influence of Gas-Liquid Two-Phase Intermittent Flow on Hydraulic Sand Dune Migration in Horizontal Pipelines, Journal of Fluid Engineering, Vol. 132, 2010.

3) Stevenson, P., Thorpe, R. B., Kennedy, J.E. and McDermott, C.: The transport of particles at low loading in near-horizontal pipes by intermittent flow, Journal of Chemical Engineering Science, 56 2149-2159, 2001.

4) Bello, O. O., Reinicke, K. M. and Teodoriu, C.: Particl Holdup Profiles in horizontal Gas-Liquid-Solid Multiphase Flow Pipeline., Journal of Chemical Engineering Technology, 2005.

5) Okayama, y., Ayugai, M., Suzuki, M. and Fukumuto, H.: Fluidity characteristic of muddy slurry with compressed air in horizontal pipe, Report of the port and harbor research institute, ministry of Transport, Vol30 (2), pp.334-557, 1991. (in Japanese)

6) Vieira, P.: Exprimental Determinition of Minimum air and Water Flow Rates for Effective Cuttings Transport in High angle and Horizontal Wells, MS thesis, University of Tulsa, Ok, 2001.

7) Bjerkholt, J. T., Cumby, T. R. and Scotford, I. M.: The effect of air injection on the pipeline transport of cattle and pig slurries, Journal of Bio-system Engineering, 91(3), pp.361-368, 2005.

8) Zhou, L., Ahmed, R. M., Miska, S. Z., Yu, M. and Saasen, A.: Hydraulics of Drilling with Areated Muds Under Simulated Borehole Condition, Journal of Fluid Engineering, Vol. 132, 2010.

9) Kantoush, S. A., Sumi, T. Murasaki, M., and Schleiss, A.: LSPIV implementation for environmental flow in various laboratory and field cases, Journal of Hydro-environment Research, 5(4), pp. 263-276, 2011.

(Received September 30, 2011) 